Article

\title{
Development of A Nested-MultiLocus Sequence Typing Approach for A Highly Sensitive and Specific Identification of Xylella fastidiosa Subspecies Directly from Plant Samples
}

\author{
Sophie Cesbron ${ }^{1, *} \mathbb{*}$, Enora Dupas ${ }^{1,2} \mathbb{D}$, Quentin Beaurepère ${ }^{1}$, Martial Briand ${ }^{1}$, \\ Miguel Montes-Borrego ${ }^{3}$, Maria del Pilar Velasco-Amo ${ }^{3}$, Blanca B. Landa ${ }^{3}$ and \\ Marie-Agnès Jacques ${ }^{1}$ \\ 1 IRHS-UMR1345, INRAE, Institut Agro, Universiteé d'Angers, SFR 4207 QuaSaV, 49071 Beaucouzeé, France; \\ enora.dupas@inrae.fr (E.D.); quentin.beaurepere@inrae.fr (Q.B.); martial.briand@inrae.fr (M.B.); \\ marie-agnes.jacques@inrae.fr (M.-A.J.) \\ 2 Plant Health Laboratory, French Agency for Food, Environmental and Occupational Health \& Safety, \\ 49000 Angers, France \\ 3 Institute for Sustainable Agriculture, Consejo Superior de Investigaciones Científicas (IAS-CSIC), \\ 14004 Córdoba, Spain; mmontes@ias.csic.es (M.M.-B.); mpvelasco@ias.csic.es (M.d.P.V.-A.); \\ blanca.landa@ias.csic.es (B.B.L.) \\ * Correspondence: sophie.cesbron@inrae.fr
}

Received: 9 June 2020; Accepted: 25 July 2020; Published: 29 July 2020

\begin{abstract}
Identification of sequence types (ST) of Xylella fastidiosa based on direct MultiLocus Sequence Typing (MLST) of plant DNA samples is partly efficient. In order to improve the sensitivity of X. fastidiosa identification, we developed a direct nested-MLST assay on plant extracted DNA. This method was performed based on a largely used scheme targeting seven housekeeping gene (HKG) loci (cysG, gltT, holC, leuA, malF, nuoL, petC). Samples analyzed included 49 plant species and two insect species (Philaenus spumarius, Neophilaenus campestris) that were collected in 2017 (106 plant samples in France), in 2018 (162 plant samples in France, 40 plant samples and 26 insect samples in Spain), and in 2019 (30 plant samples in Spain). With the nested approach, a significant higher number of samples were amplified. The threshold was improved by 100 to 1000 times compared to conventional PCR. Using nested-MLST assay, plants that were not yet considered hosts tested positive and revealed novel alleles in France, whereas for Spanish samples it was possible to assign the subspecies or ST to samples considered as new hosts in Europe. Direct typing by nested-MLST from plant material has an increased sensitivity and may be useful for epidemiological purposes.
\end{abstract}

Keywords: Xylella fastidiosa; direct typing technique; MLST; nested PCR

\section{Introduction}

Xylella fastidiosa $(\mathrm{Xf})$ is the causal agent of several devastating diseases of plants in the Americas and this pathogen was recently detected in Europe, where it causes a severe disease in olive trees in Italy and is present in several other regions. This species encompasses three well recognized subspecies, namely fastidiosa, multiplex, and pauca [1,2] but other subspecies are currently described [3]. The subspecies fastidiosa occurs in North and Central America and was recently detected in Spain (https://gd.eppo.int/taxon/XYLEFA/). It infects a wide range of trees, ornamentals, and other perennials and includes strains responsible for the well-known Pierce's disease on grapevine [3,4]. The subspecies multiplex is present in North and South America and in Europe (https://gd.eppo.int/taxon/XYLEFA/) and 
is associated with scorches and dieback of a wide range of trees and ornamentals [3]. The subspecies pauca is mostly found in South and Central America on Citrus spp. and Coffea spp. [5]), but has been recently detected also in olive trees in Spain (https://gd.eppo.int/taxon/XYLEFA/), Brazil [6], Argentina [7], and Italy [8]. Its host range includes also ornamentals and other trees [3]. Altogether more than 560 plant species are hosts of Xf [3]. This member of the Xanthomonadaceae family inhabits the xylem of its host plants [9] and is naturally transmitted by insects from plants to plants.

A range of detection tests has been proposed for $X f$ [10]. Several immunological methods are available [10]. However, such methods have high limits of detection (LoDs) that are close to $10^{4}$ to $10^{5}$ cells. $\mathrm{mL}^{-1}$ [10]. End point and also quantitative PCR (qPCR) are nowadays widely used, with a better sensivity as the LoD is around $10^{2}$ cells. $\mathrm{mL}^{-1}$ for several qPCR tests [11-14]. The Harper's qPCR test is often used in Europe for its high sensitivity. Several tests based on isothermal amplification have also been reported [12,14-16]. The Harper's test has also been successfully transferred to be used in digital PCR [17]. Some of these tests were designed to detect only one subspecies. This is the case of the nested PCR test proposed by [18] for detecting CVC (Citrus Variegated Chlorosis) strains (subspecies pauca) in sharpshooters and citrus plants and also of the qPCR test targeting oleander leaf scorch strains (that are included in the subspecies fastidiosa) [19]. Other tests were designed to detect and discriminate two or more subspecies $[16,20]$.

Precise identification of $X f$ at an infraspecific level is essential for epidemiological and surveillance analyses, and to allow a proper description of the population structure and their dynamics. The widely used MultiLocus Sequence Typing (MLST) scheme designed for Xf [21,22] is based on amplification by conventional PCR and sequencing of seven HKG (housekeeping gene) fragments (loci), either from strains or from plant samples [23]. For each locus, the different sequence variants are considered as distinct alleles. The combination of allele numbers defines the sequence type (ST). The MLST-Xf data are stored in a public database (https://pubmlst.org/xfastidiosa/) that can be used to automatically identify and assign new allele variants, and provide tools to analyze the potential origin of the strains. The association of the different subspecies with their host plants is useful to better understand $X f$ epidemiology.

A reliable and enough informative typing method is particularly relevant in cases of new outbreaks or for the description of new host. Due to the large number of host plants to be analyzed, various types of inhibitors can interfere with reagents of PCR and low bacterial loads compromising PCR efficiency and hence typing. Improving DNA extraction methods can, at least partly, solve the problem of PCR inhibitors, and nested PCR appears a solution to allow the detection of low bacterial population sizes. A nested-MLST was already successfully developed to detect and type $X f$ in vectors [24]. Primers were designed inside the gene fragments used in the conventional-MLST scheme and hence some informative sites are lost. MLST with nested PCRs has also been developed in medical field to enable the direct typing of samples infected by Leptospira or Trichomonas, for example [25,26].

The objective of this study was to develop a Xf detection assay based on the largely used MLST scheme [22] that lowers the limit of detection (LoD) to enable at least the identification of Xf subspecies and, if possible, provide larger sets of typing data directly from plant samples. We used genomic sequences to improve each PCR efficiency and showed a drastic increase in the sensitivity as compared to that of the conventional-MLST approach.

\section{Materials and Methods}

\subsection{Strains and Media}

A collection of target and non-target bacterial strains was used to test in vitro the specificity of the newly designed primers and the nested PCR assays. This set was made of five X. fastidiosa strains from different subspecies and 34 strains representing bacteria phylogenetically close to $X f$, i.e., various Xanthomonas, as well as strains of other plant pathogenic bacteria and endosymbionts potentially 
inhabiting the same niches as Xf (Table 1), available at the French Collection of Plant-Associated Bacteria (CIRM-CFBP; https://www6.inra.fr/cirm_eng/CFBP-Plant-Associated-Bacteria).

The Xf strains were grown on modified PWG media (agar 12 g.L. $\mathrm{L}^{-1}$; soytone 4 g.L $\mathrm{L}^{-1}$; bacto tryptone 1 g. $\mathrm{L}^{-1} ; \mathrm{MgSO}_{4} .7 \mathrm{H}_{2} \mathrm{O} 0.4$ g.L $\mathrm{L}^{-1} ; \mathrm{K}_{2} \mathrm{HPO}_{4} 1.2$ g.L $\mathrm{L}^{-1} ; \mathrm{KH}_{2} \mathrm{PO}_{4} 1$ g. $\mathrm{L}^{-1}$; hemin chloride $(0.1 \%$ in $\mathrm{NaOH}$ $0.05 \mathrm{M}) 10 \mathrm{~mL} . \mathrm{L}-1$; BSA $(7.5 \%) 24 \mathrm{~mL} . \mathrm{L}^{-1}$; L-glutamine $\left.4 \mathrm{~g} . \mathrm{L}^{-1}\right)$ at $28^{\circ} \mathrm{C}$ for one week. Agrobacterium and Rhizobium were grown at $25{ }^{\circ} \mathrm{C}$ for one to two days on MG medium [27]; TSA was used (tryptone soybroth 30 g.L $\mathrm{L}^{-1}$; agar 15 g.L $\mathrm{L}^{-1}$ ) for Clavibacter, Ensifer, Stenotrophomonas, Xanthomonas and Xylophilus; and King's medium B [28] for Dickeya, Erwinia, Pantoea and Pseudomonas. For PCRs, bacterial suspensions were prepared from fresh cultures in sterile distilled water, adjusted at $\mathrm{OD}_{600 \mathrm{~nm}}=0.1$ and used as templates for amplification after boiling for $20 \mathrm{~min}$, thermal shock on ice and centrifugation $10000 \mathrm{~g}, 10 \mathrm{~min}$.

\subsection{DNA Extraction}

Genomic DNA from Xf strain CFBP 8070 was extracted with the Wizard genomic DNA Purification Kit (Promega, France) and used to prepare a 10-fold serial dilutions from $220 \mathrm{ng} . \mathrm{mL}^{-1}$ (corresponding to $0.8 \times 10^{8}$ copies.mL $\mathrm{m}^{-1}$ of genomic DNA) to $22 \mathrm{fg} \cdot \mathrm{mL}^{-1}\left(8\right.$ copies. $\left.\mathrm{mL}^{-1}\right)$ to evaluate the LoD of the nested-MLST. Copies number were calculated using an estimated genome size of $2903976 \mathrm{bp}$, knowing that $1 \mathrm{pg}=9.78 \times 10^{8} \mathrm{bp}$ [29]. A total of 268 plant samples were collected in Corsica, France, based on symptoms compatible with those caused by X. fastidiosa; 106 samples were collected in June 2017 and 162 in September 2018. For each French sample, DNA was extracted as described in [10] using two methods in order to optimize the chances of detection. CTAB-based (Cetyl TrimethylAmmonium Bromide) extraction and robotic QuickpickTM SML kit from Bio-Nobile were used with the following modification: a sonication step ( $1 \mathrm{~min}, 42 \mathrm{KHz}$ ) was added after the samples (petioles, twigs) were finely cut, and was followed by a 15-min incubation period at room temperature. For initial laboratory diagnosis MLST results were compared with the Harper's qPCR test [12] as in [10] with following modifications: primers XF-F and XF-R, and probe XF-P [12] were used at a final concentration of $0.6 \mu \mathrm{M}$ and $0.2 \mu \mathrm{M}$ respectively, non-acetylated BSA (Bovine serum Albumine) was used at final concentration of $1.5 \mu \mathrm{g} . \mu \mathrm{L}^{-1}$, and $2 \mu \mathrm{L}$ of DNA were used in $10 \mu \mathrm{L}$ reaction volume. The target of this PCR is located in the gene coding for the $16 \mathrm{~S}$ rRNA-processing RimM protein. Each DNA sample was tested in triplicates. To validate the nested PCR, DNA samples were provided by the National Reference Laboratory for Phytopathogenic Bacteria, Valencia, Spain, and from the Official Phytosanitary Laboratory of the Balearic Islands for determining Xf subspecies. Those DNA samples correspond to DNA extractions made from symptomatic plants sampled during official monitoring surveys. A total of $70 \mathrm{Xf}$-infected samples were analyzed from Balearic Islands and mainland Spain during 2018 (40 samples) and 2019 (30 samples), as well as 26 insect samples from both regions. DNA was extracted from petioles of symptomatic leaves as described in [10] using a CTAB-based extraction method for plant samples from Alicante and insect samples from Alicante and Balearic Islands. A Mericon DNeasy Food kit from Qiagen was used for plant samples from Balearic Islands. All DNA extraction methods have been validated; validation data is available in the EPPO (European and Mediterranean Plant Protection Organization) Database on Diagnostic Expertise [10].

\subsection{Nested-MLST Primers and Reactions}

The seven HKG sequences (cysG, gltT, holC, leuA, malF, nuoL, petC) were extracted from $39 \mathrm{Xf}$ genome sequences (Table S1) [2] to design the nested primers. Alignments were performed with BioEdit sequence alignment editor. The primers designed by [22] were destined to be used as inner primers (PCR2) (Table 2) in our nested assay. 
Table 1. List of target and non-target strains used to verify the specificity of nested-MLST primers.

\begin{tabular}{|c|c|c|c|}
\hline CFBP Code & Bacterial Species & Host Plant & Origin \\
\hline 6448 & Agrobacterium rubi & Rubus ursinus var. loganobaccus & USA (1942) \\
\hline 2413 & Agrobacterium tumefaciens & Malus sp. & NA (1935) \\
\hline 5523 & Agrobacterium vitis & Vitis vinifera & Australia (1977) \\
\hline 2404 & Clavibacter insidiosus & Medicago sativa & USA (1955) \\
\hline 4999 & Clavibacter michiganensis & Lycopersicon esculentum & Hungary (1957) \\
\hline 3418 & Curtobacterium flaccumfaciens pv. flaccumfaciens & Phaseolus vulgaris & Hungary (1957) \\
\hline 1200 & Dickeya dianthicola & Dianthus caryophyllus & United Kingdom (1956) \\
\hline 5561 & Ensifer meliloti & Medicago sativa & VA, USA (1984) \\
\hline 1232 & Erwinia amylovora & Pyrus communis & United Kingdom (1959) \\
\hline 3845 & Pantoea agglomerans & Knee laceration & Zimbabwe (1956) \\
\hline 3167 & Pantoea stewartii pv. stewartii & Zea mays var. rugosa & USA (1970) \\
\hline 3205 & Pseudomonas amygdali & Prunus amygdalus & Greece (1967) \\
\hline 8305 & Pseudomonas cerasi & Prunus cerasus & Poland (2007) \\
\hline 7019 & Pseudomonas congelans & na ${ }^{1}$ & Germany (1994) \\
\hline 1573 & Pseudomonas syringae pv. persicae & Prunus persica & France (1974) \\
\hline 1392 & Pseudomonas syringae pv. syringae & Syringa vulgaris & United Kingdom (1950) \\
\hline 7436 & Rhizobium nepotum & Prunus ceresifera myrobolan & Hungary (1989) \\
\hline 13100 & Stenotrophomas maltophilia & Phaseolus vulgaris & Cameroon (2009) \\
\hline 3371 & Xanthomonas euvesicatoria pv. citrumelonis & Citrus sp. & USA (1989) \\
\hline 2528 & Xanthomonas arboricola pv. juglandis & Juglans regia & New Zealand (1956) \\
\hline 2535 & Xanthomonas arboricola pv. pruni & Prunus salicina & New Zealand (1953) \\
\hline 4924 & Xanthomonas axonopodis pv. axonopodis & Axonopus scoparius & Colombia (1949) \\
\hline 5241 & Xanthomonas campestris pv. campestris & Brassica oleracea var. gemmifera & United Kingdom (1957) \\
\hline 2901 & Xanthomonas citri pv. aurantifolii & Citrus limon & Argentina (1988) \\
\hline 2525 & Xanthomonas citri pv. citri & Citrus limon & New Zealand (1956) \\
\hline 7660 & Xanthomonas citri pv. viticola & Vitis vinifera & India (1969) \\
\hline 2625 & Xanthomonas gardneri & Medicago sativa & Reunion Island (1986) \\
\hline 4925 & Xanthomonas hortorum pv. hederae & Hedera helix & USA (1944) \\
\hline 2533 & Xanthomonas hortorum pv. pelargonii & Pelargonium peltatum & New Zealand (1974) \\
\hline 1156 & Xanthomonas hyacinthi & Hyacinthus orientalis & Netherlands (1958) \\
\hline 2532 & Xanthomonas oryzae pv. oryzae & Oryza sativa & India (1965) \\
\hline 2054 & Xanthomonas translucens & Hordeum vulgare & USA (1933) \\
\hline 2543 & Xanthomonas vasicola pv. holcicola & Sorghum vulgare & New Zealand (1969) \\
\hline 7970 & Xylella fastidiosa subsp. fastidiosa & Vitis vinifera & USA (1987) \\
\hline 8416 & Xylella fastidiosa subsp. multiplex & Polygala myrtifolia & France (2015) \\
\hline 8084 & Xylella fastidiosa subsp. morus & Morus alba & USA $\left(n a^{1}\right)$ \\
\hline 8070 & Xylella fastidiosa subsp. multiplex & Prunus spp. & USA (2004) \\
\hline 8402 & Xylella fastidiosa subsp. pauca & Olea europea & Italy (2014) \\
\hline 1192 & Xylophilus ampelinus & Vitis vinifera & Greece (1966) \\
\hline
\end{tabular}

${ }^{1}$ : not available. 
Table 2. Primer sequences used in the X. fastidiosa nested-MLST scheme.

\begin{tabular}{|c|c|c|c|c|c|c|}
\hline Locus & $\begin{array}{l}\text { PCR } \\
\text { Round }\end{array}$ & $5^{\prime}$-Forward Primer-3' & $5^{\prime}$-Reverse Primer-3' & $\begin{array}{c}\text { Position on } X f \text { M12 Genome } \\
\text { (CP000941.1) }\end{array}$ & $\begin{array}{c}\text { Annealing } \\
\text { Temperature }\left({ }^{\circ} \mathrm{C}\right)\end{array}$ & $\begin{array}{c}\text { Size }(\mathrm{pb}) \text { of Reaction } \\
\text { Product }\end{array}$ \\
\hline \multirow[t]{2}{*}{ cys $G$} & 1 & CCAAACATAGAAGCACGCCG & GCGAGTGTTTTCAGCGTTCC & 2111116-2111891 & 64 & 776 \\
\hline & 2 & GCCGAAGCAGTGCTGGAAG $^{1}$ & GCCATTTTCGATCAGTGCAAAAG $^{1}$ & 2111203-2111844 & 56 & 642 \\
\hline \multirow[t]{2}{*}{ gltT } & 1 & GGTGCCATCCAATCCGTTTT & TCAGGATGTCCCAATTCCAACG & 1731589-1732504 & 60 & 916 \\
\hline & 2 & TCATGATCCAAATCACTCGCTT ${ }^{1}$ & TTACTGGACGCTGCCTCG & 1731783-1732482 & 56 & 700 \\
\hline \multirow[t]{2}{*}{ holC } & 1 & CCGATGGTGAAGAACAGTAGACA & GCTCGAGAAACTSGATTAATGG & 133166-133714 & 62 & 549 \\
\hline & 2 & GGTCACATGTCGTGTTTGTTC & CACGCGCCGACTTCTATTT & 133269-133692 & 59 & 424 \\
\hline \multirow[t]{2}{*}{ leuA } & 1 & CGAAGGTGCAAACAAAGTGA & CGCACTGGCTTCGATAATGTCT & $1271664-1272549$ & 58 & 886 \\
\hline & 2 & GGTGCACGCCAAATCGAATG $^{1}$ & ACTGGTCCCTGTACCTTCGT & $1271752-1272525$ & 60 & 774 \\
\hline \multirow[t]{2}{*}{ malF } & 1 & AACGTCGTCACCCCAAGAA & ATGAGGCGGGCTTCTTTGG & $1680264-1681108$ & 56 & 845 \\
\hline & 2 & AGCAGAAGCACGTCCCAGAT & CTGGTCCTGCGGTGTTGG & $1680308-1681074$ & 60 & 767 \\
\hline \multirow[t]{2}{*}{ nиоL } & 1 & TTGGTACGTTGGCTTTGGTG & GACAAAACCAGATTGCGTGC & 325347-326191 & 60 & 845 \\
\hline & 2 & GCGACTTACGGTTACTGGGC & ACCACCGATCCACAACGCAT $^{1}$ & $325454-326050$ & 54 & 597 \\
\hline \multirow[t]{2}{*}{ petC } & 1 & TCAATGCACGTCCTCCCAAT & GGCTGCCATTCGTTGAAGTA & 2020498-2021079 & 60 & 582 \\
\hline & 2 & ACGTCCTCCCAATAAGCCT & CGTTATTCACGTATCGCTGC & $2020505-2021055$ & 56 & 551 \\
\hline
\end{tabular}

${ }^{1}$ : primers from [22] 
We checked their characteristics with Primer3 V4.1.0 software (http://primer3.ut.ee/). Because of high Tm differences between forward and reverse primers for some primer pairs (gltT) (Table S2), or high hairpin Tm values (holC forward primer), some primers from [22] were redesigned nearly at the same positions to improve their efficiency. Moreover, as primer sequences were already near the locus sequence ends, we also had to relocate some of them to design nested primers inside the sequence alignments without loss of informative sites. Outer primers (PCR1) were designed with Primer3 V4.1.0 software (http://primer3.ut.ee/) in flanking regions targeted by the inner primers. Outer and inner primers were tested In silico using a primer search tool available in the galaxy toolbox of CIRM-CFBP (https://iris.angers.inra.fr/galaxypub-cfbp) on 194,438 bacterial Whole Genome Shotgun (WGS) sequences available in the NCBI database (as on March, 2019) including 58 Xylella and 1292 Xanthomonas (Table S3), and in vitro on target and non-target bacterial strains (Table 1).

PCRs were performed in $25 \mu \mathrm{L}$ reaction buffer (Promega) with $\mathrm{MgCl}_{2}$ at $1.5 \mathrm{mM}$ final, $200 \mu \mathrm{M}$ $\mathrm{dNTP}, 300 \mu \mathrm{M}$ each of the forward and reverse primers, 0.6 U GoTaq G2 (Promega) and $2 \mu \mathrm{L}$ of sample DNA. The first-round PCR program consisted of an initial denaturation step of $3 \mathrm{~min}$ at $95^{\circ} \mathrm{C}$ followed by 35 cycles of $30 \mathrm{~s}$ denaturation at $95^{\circ} \mathrm{C}, 30 \mathrm{~s}$ annealing at the relevant temperature according to each gene (determined by gradient PCR) and 60 s elongation at $72{ }^{\circ} \mathrm{C}$ followed by a final extension step of $10 \mathrm{~min}$ at $72{ }^{\circ} \mathrm{C}$ (Table 2). The second round was performed with 30 cycles under same conditions and same concentrations but with a final volume of $50 \mu \mathrm{L}$ for sequencing purposes and with $4 \mu \mathrm{L}$ of first-round PCR product. The primer pairs of the second round of each nested PCR were used for sequencing (by Genoscreen, Lille, France for French samples and by Stabvida, Caparica, Portugal, for Spanish samples) the corresponding PCR products after 1.8\% agarose gel visualization. To avoid contamination, one sample was opened at a time and stringent cleaning measures were applied after each experiment.

\subsection{Statistical Analysis}

The sensitivity of detection by conventional- and nested-MLST PCRs were compared in plant and vector samples for the seven HKGs that were analyzed by both approaches, by using a Chi square test using SAS (version 9.4, SAS Institute, Cary, NC, USA). Analysis was performed for the Spanish samples only, as HKG-PCRs were not systematically carried out on the French samples. Results were considered significantly different when $p \leq 0.05$.

\subsection{Sequence Acquisition, Alignment and Analyses}

Forward and reverse nucleotide sequences were assembled, and aligned using Geneious 9.1.8 software (French samples) or Bionumerics V7.6.3 software (Spanish samples) to obtain high quality sequences. ST or loci assignation was performed according to http://pubmlst.org/xfastidiosa/. To reduce the costs of sequencing for French samples, only PCR products obtained for samples showing the highest rate of successful HKG amplifications were sequenced. On the other hand, all positive holC amplifications were sequenced to obtain a larger view of alleles present in Corsica.

A flow chart summarizing the different steps of the nested-MLST method is presented in Figure 1. 


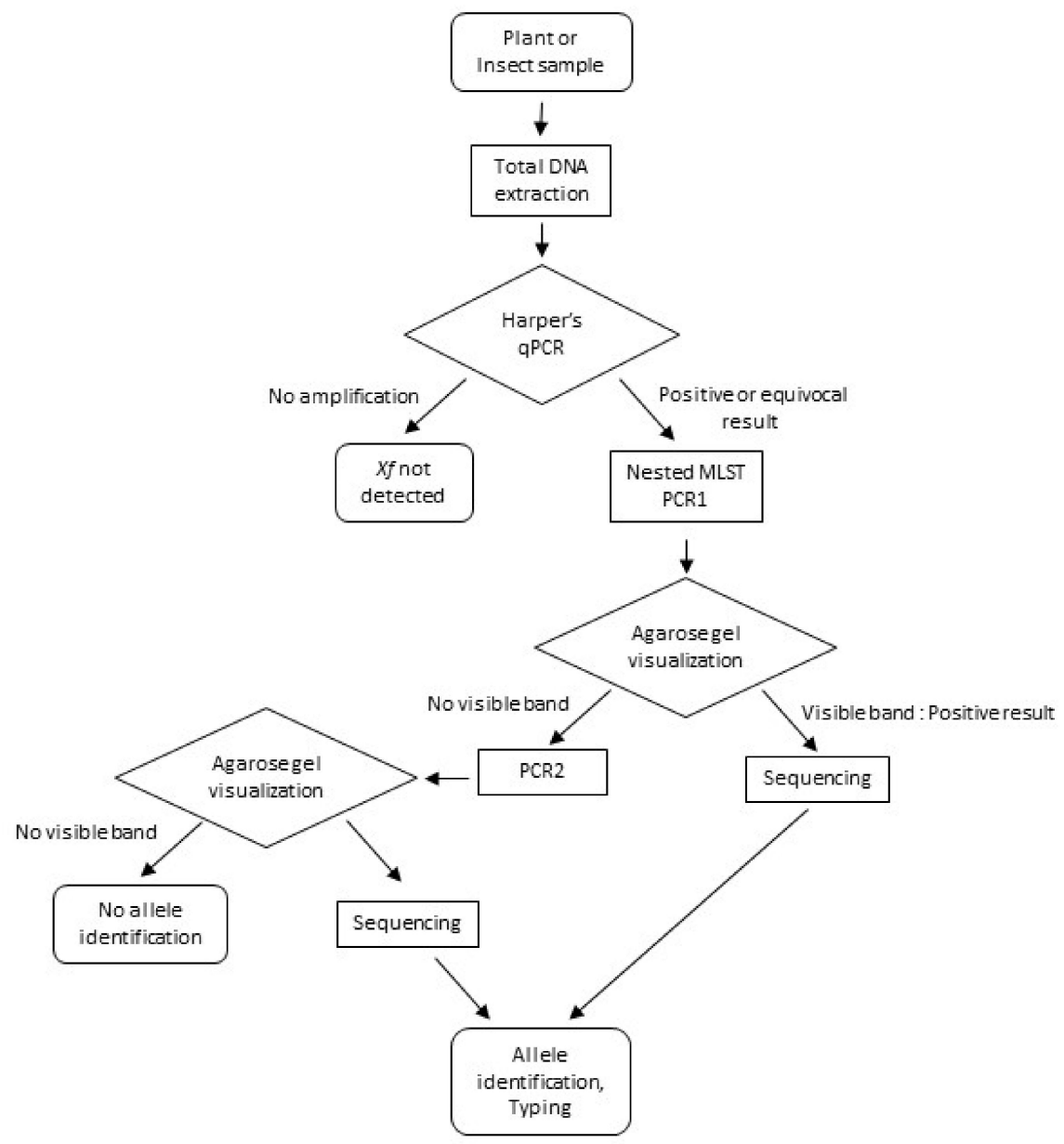

Figure 1. Flow chart summarizing the different steps of the nested-MLST method.

\section{Results}

\subsection{Nested-MLST Proved to be Specific}

The specificity of the outer and inner primer pairs was tested In silico and in vitro. In silico, all primers pairs showed the best scores of alignment with $X f$ genomic sequences. Some non-target organisms showed sequences nearly identical at outer primer locations with only one mismatch and a similar expected fragment size, but sequences of inner primers were more different indicating that there will be no amplification. This was the case for various Xanthomonas strains that contained one mismatch at position 15 of the pet $C$ forward outer primer and an identical sequence for the outer reverse primer. X. taiwanensis holC sequence corresponding to inner primers contained also only one mismatch. The fragment size predicted was as expected for Xf. Other predictions with one mismatch located in primers did not end in fragment amplifications of the same expected size. Then, the specificity of the outer and inner primer pairs (Table 2) was validated in vitro on five target strains and 34 non-target strains (Table 1). Specificity of the nested-MLST assay could not been tested in vitro on X. taiwanensis as no strain was available. Amplifications were obtained for all Xf strains. No amplification was detected on the non-target strains except for strain CFBP 2532 (Xanthomonas oryzae pv oryzae) and CFBP 2533 (Xanthomonas hortorum pv. pelargonii) in the first round of the nested PCR for the petC outer primers, providing a product of the expected size. However, these products were not amplified in the second round of the nested PCR and no false positive signal was finally obtained. 


\subsection{Nested-MLST Limit of Detection is Comparable to That of $q P C R$}

The sensitivity of each primer combination was evaluated on serial dilutions of a genomic DNA solution calibrated (Qubit fluorimeter, Invitrogen) at $220 \mathrm{ng} \cdot \mathrm{mL}^{-1}$ (Figure 2). First round PCRs gave a signal more or less intense for concentrations up to $2.2 \mathrm{ng} \cdot \mathrm{mL}^{-1}\left(0.8 \times 10^{6}\right.$ copies.mL $\left.{ }^{-1}\right)$ for all HKG except malF and cysG $\left(220\right.$ pg. $\left.\mathrm{mL}^{-1}\right)$. The second round of PCRs allowed a sufficiently strong signal for sequencing for concentrations up to $22 \mathrm{pg} . \mathrm{mL}^{-1}\left(0.8 \times 10^{4}\right.$ copies.mL $\left.{ }^{-1}\right)$ for gltT, holC, petC, leuA, cysG, and up to $2.2 \mathrm{pg} . \mathrm{mL}^{-1}\left(0.8 \times 10^{3}\right.$ copies. $\left.\mathrm{mL}^{-1}\right)$ for $n u o L$ and malF.

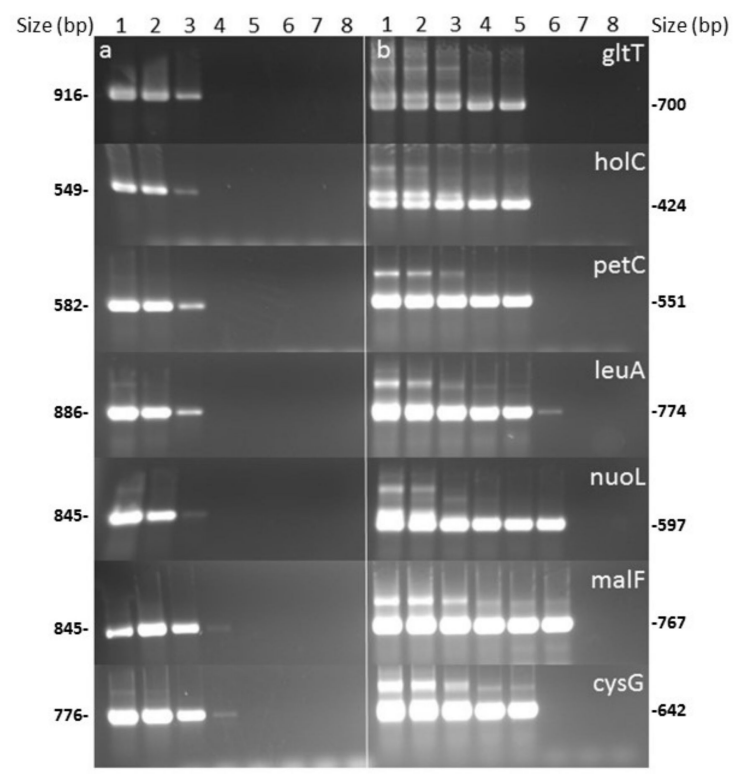

Figure 2. Detection threshold of conventional-MLST (a) and nested-MLST (b) for seven HKGs using genomic DNA dilution range $\left(1: 220\right.$ ng.mL ${ }^{-1} ; 2: 22$ ng.mL ${ }^{-1} ; 3: 2.2$ ng.mL $\mathrm{mL}^{-1} ; 4: 220$ pg.mL ${ }^{-1}$; 5:22 pg.mL $\mathrm{mL}^{-1} ; 6: 2.2$ pg.mL $\mathrm{mL}^{-1} ; 7: 220$ fg.mL $\mathrm{mL}^{-1} ; 8: 22$ fg.mL $\left.\mathrm{mL}^{-1}\right)$.

The same range of genomic DNA solutions was tested with the Harper's qPCR test to compare sensitivity of these two tests (Table S4). The latest signal $(\mathrm{LoD})$ for the Harper's qPCR test $(\mathrm{Cq}=37.64)$ was obtained with the concentration of $0.8 .10^{3}$ copies. $\mathrm{mL}^{-1}$ and no amplification was obtained for lower concentrations.

Previously, we evaluated the LoD of the conventional PCRs for cysG and malF of the initial MLST scheme [22] on a range of dilutions of CFBP 8070 genomic DNA with the Platinum Taq polymerase (Invitrogen) and tested the effect of adding BSA (final concentration at $0.3 \mu \mathrm{g} . \mu \mathrm{L}^{-1}$ ) on the efficiency of the conventional PCRs. No improvement was obtained as all signals remained around $0.8 \times 10^{6}$ bacteria. $\mathrm{mL}^{-1}$ (Figure $\mathrm{S} 1$ ).

\subsection{Analysis of Naturally Infected Samples}

Using qPCR Harper's test, 22 samples from 2017 and eight samples from 2018 collected in France were positive ( $\mathrm{Cq}$ values $<35$ ) with one or both DNA extraction methods; 70 samples from 2017 and 36 samples from 2018 were equivocal $(35 \leq \mathrm{Cq} \leq 40)$, 14 samples from 2017 and 118 from 2018 were negative $(\mathrm{Cq}>40)$ (Table 3 and Table S5). Positive and equivocal samples were tested using the first round of PCR of the MLST assay: five samples from 2017 (one Spartium junceum, three Polygala myrtifolia, and one Genista corsica) gave a signal for at least one gene, but no complete typing was obtained for any sample. No sample from 2018 gave a signal. Most of Spanish samples used to evaluate nested-MLST scheme were positive using Harper's qPCR (only two out of 40 plant samples were equivocal in 2018 and eight out of 26 vector samples). 
Table 3. Number of samples, positive and equivocal in Harper's qPCR. Percentage of successful amplifications obtained for each locus in conventional and nested PCR.

\begin{tabular}{|c|c|c|c|c|c|c|c|c|c|c|c|c|c|c|c|c|c|c|c|c|c|}
\hline \multirow{3}{*}{$\begin{array}{l}\text { Sample } \\
\text { Type }\end{array}$} & \multirow{3}{*}{ Country } & \multirow{3}{*}{ Year } & \multirow{3}{*}{$\begin{array}{c}\text { Number } \\
\text { of } \\
\text { Samples }\end{array}$} & & & \multicolumn{16}{|c|}{ Percentage of Successful Amplifications Obtained for Each Locus in Conventional and Nested MLST-PCR } \\
\hline & & & & \multicolumn{2}{|c|}{$\begin{array}{l}\text { qPCR Harper } \\
\text { Number of } \\
\text { Samples }\end{array}$} & \multicolumn{2}{|c|}{ cysG } & \multicolumn{2}{|c|}{ gltT } & \multicolumn{2}{|c|}{ holC } & \multicolumn{2}{|c|}{ leuA } & \multicolumn{2}{|c|}{ malF } & \multicolumn{2}{|c|}{ nиоL } & \multicolumn{2}{|c|}{ petC } & \multicolumn{2}{|c|}{$\begin{array}{l}\text { Average } \\
\text { per Year }\end{array}$} \\
\hline & & & & $\mathrm{Cq}<35$ & $\mathrm{Cq} \geq 35$ & conv & nest & conv & nest & conv & nest & conv & nest & conv & nest & conv & nest & conv & nest & conv & nest \\
\hline Plant & France & 2017 & 106 & 22 & 70 & 1.1 & 28.3 & 2.2 & 26.1 & 4.3 & 55.4 & 4.3 & 34.8 & 1.1 & 35.9 & 0 & 26.1 & 1.1 & 46.7 & 2 & 36.2 \\
\hline Plant & France & 2018 & 162 & 8 & 36 & 0 & 11.4 & 0 & 9.1 & 0 & 27.3 & 0 & 27.3 & 0 & 15.9 & 0 & 27.3 & 0 & 25 & 0 & 20.5 \\
\hline Plant & Spain & 2018 & 40 & 38 & 2 & 55 & $90^{*}$ & 10 & $77.5^{*}$ & 15 & $80^{*}$ & 12.5 & $75^{*}$ & 30 & $75^{*}$ & 40 & $85^{*}$ & 15 & $85^{*}$ & 25.4 & 81.1 \\
\hline Plant & Spain & 2019 & 30 & 30 & 0 & 30 & $90^{*}$ & 13.3 & $90^{*}$ & 16.7 & $93.3^{*}$ & 16.7 & $90^{*}$ & 20 & $90^{*}$ & 66.7 & $90^{*}$ & 20 & $90^{*}$ & 26.2 & 90.5 \\
\hline Insect & Spain & 2018 & 26 & 18 & 8 & 65.4 & 80.8 & 7.7 & $73.1^{*}$ & 19.2 & $69.2^{*}$ & 11.5 & $57.7^{*}$ & 7.7 & $53.8^{*}$ & 26.9 & $57.7^{*}$ & 15.4 & $73.1^{*}$ & 22 & 66.5 \\
\hline
\end{tabular}

$\left(^{*}\right)$ Asterisk indicates a significant $(p<0.05)$ higher number of successful amplifications for nested-MLST as compared to conventional-MLST [22] according to a Chi-square test. The test was conducted only for the Spanish samples on the number of samples, even if frequencies are indicated in the table for MLST-PCR. 


\subsection{Nested-MLST Improved Successful HKG Typing by Increasing Sensitivity Level}

Using nested-MLST for French samples, full allelic profiles were obtained for five samples from 2017 and one from 2018 corresponding to the lowest Cq in Harper's qPCR test (Table 4 and Table S5) Among fully typed samples, four were X. fastidiosa subsp. multiplex ST7 (Genista corsica, Polygala myrtifolia, Spartium junceum), and two were X. fastidiosa subsp. multiplex ST6 (Polygala myrtifolia).

Our scheme was also evaluated on Spanish samples already proved infected by $X f$. These samples from different outbreaks showed a wide range of $\mathrm{Cq}$ values ranging from 18.8 to 36.0 for plant samples and from 23.29 to 37.0 for insect samples (Table 3 and Table S5). Samples were first analyzed using the conventional-MLST assay [22]. Amplification efficiency was variable and ranged from $10 \%$ for gltT to $67 \%$ for $n u o L$ with an average of $25 \%$ and $26 \%$ for the seven HKG in 2018 and 2019, respectively. The nested-MLST assay improved the amplification efficiency that increased to $75 \%$ for leuA and up to $93 \%$ for holC with an average of $81 \%$ and $91 \%$ in 2018 and 2019, respectively. In total, full allelic profiles were obtained in seven plant samples using the conventional-MLST assay, whereas a total of 55 samples were fully typed with the improved nested-MLST assay (Table 4). For the 70 plant DNA samples that were tested by both protocols, for all the seven HKGs, conventional-MLST showed a significant $(p<0.0005$ for 2018 and $p<0.0283$ for 2019) lower number of samples amplified as compared to nested-MLST. Among fully typed plant samples using the nested-MLST, we identified X. fastidiosa subsp. fastidiosa ST1 in Ficus carica and Juglans regia, X. fastidiosa subsp. multiplex ST6 in Helichrysum italicum, Olea europaea, Phagnalon saxatile, Polygala myrtifolia, Prunus armeniaca, Prunus domestica, Prunus dulcis, Rhamnus alaternus, and Rosmarinus officinalis, X. fastidiosa subsp. multiplex ST7 in Prunus dulcis, X. fastidiosa subsp. multiplex ST81 in Lavandula angustifolia and Prunus dulcis, and X. fastidiosa subsp. pauca ST80 in Cistus albidus, Prunus dulcis, and Rosmarinus officinalis.

Not all insect samples could be tested by both protocols due to restrictions in DNA amount. In samples tested only by the original MLST assay [22], the percentages of successful amplifications ranged from $8 \%$ (gltT and malF) to $65 \%$ (cysG). With the nested-MLST assay, successful amplifications ranged from $54 \%$ (malF) to $81 \%$ (cysG), with an average efficiency for the seven HKG of $22 \%$ to $67 \%$ for conventional and nested approach, respectively (Table 3 and Table S5). Nine insect samples were fully typed using a combination of both protocols (Table 4). X. fastidiosa subsp. fastidiosa ST1 was identified in insects from Mallorca (Balearic Islands), X. fastidiosa subsp. multiplex ST6 in insects from Alicante (mainland Spain) and X. fastidiosa subsp. multiplex ST81 in insects from Balearic Islands. For the nine insect samples that were tested by both protocols, conventional-MLST showed a significant $(p<0.0247)$ lower number of samples amplified as compared to nested-MLST for six of the seven HKGs (excluding cysG). These results indicate that for insect samples it is also better to use directly the improved nested-MLST assay.

No nonspecific amplicons were observed in any of the samples. Negative controls (water) were run in the first and the second PCR and were always negative. The negative control coming from the first reaction always tested negative in the second one, confirming the absence of contamination during the entire process. Positive control was a suspension of strain CFBP 8084 (ST29) from the subspecies morus or strain CO33 (ST72) as this STs were not previously found in Corsica, France or Spain, respectively. 
Table 4. Allele numbers and STs obtained for fully typed samples in France and Spain for plant and insect samples. The numbers correspond to the names of the samples.

\begin{tabular}{|c|c|c|c|c|c|c|c|c|c|}
\hline Country & Sample Names & cysG & gltT & holc & leuA & malF & nuoL & petC & Sequence Type (ST) \\
\hline France & Spartium junceum 2 & 7 & 3 & 3 & 3 & 3 & 3 & 3 & ST7 \\
\hline France & Polygala myrtifolia 3, 4 & 3 & 3 & 3 & 3 & 3 & 3 & 3 & ST6 \\
\hline France & Genista corsica 1 & 7 & 3 & 3 & 3 & 3 & 3 & 3 & ST7 \\
\hline France & Polygala myrtifolia 5, 6 & 7 & 3 & 3 & 3 & 3 & 3 & 3 & ST7 \\
\hline Spain & Cistus albidus 2 & 31 & 15 & 10 & 7 & 17 & 16 & 6 & ST80 \\
\hline Spain & Ficus carica 1 & 1 & 1 & 1 & 1 & 1 & 1 & 1 & ST1 \\
\hline Spain & Helichrysum italicum 1 & 3 & 3 & 3 & 3 & 3 & 3 & 3 & ST6 \\
\hline Spain & Juglans regia 1 & 1 & 1 & 1 & 1 & 1 & 1 & 1 & ST1 \\
\hline Spain & Lavandula angustifolia 1 & 32 & 3 & 3 & 3 & 3 & 3 & 3 & ST81 \\
\hline Spain & Olea europaea 1 & 3 & 3 & 3 & 3 & 3 & 3 & 3 & ST6 \\
\hline Spain & Phagnalon saxatile 1 & 3 & 3 & 3 & 3 & 3 & 3 & 3 & ST6 \\
\hline Spain & Polygala myrtifolia 1 & 3 & 3 & 3 & 3 & 3 & 3 & 3 & ST6 \\
\hline Spain & Prunus armeniaca 1 & 3 & 3 & 3 & 3 & 3 & 3 & 3 & ST6 \\
\hline Spain & Prunus domestica 1 & 32 & 3 & 3 & 3 & 3 & 3 & 3 & ST81 \\
\hline Spain & Prunus domestica 2 & 3 & 3 & 3 & 3 & 3 & 3 & 3 & ST6 \\
\hline Spain & Prunus dulcis 4-8,10,11,15,18-26,30-47 & 3 & 3 & 3 & 3 & 3 & 3 & 3 & ST6 \\
\hline Spain & Prunus dulcis 9 & 31 & 15 & 10 & 7 & 17 & 16 & 6 & ST80 \\
\hline Spain & Prunus dulcis 1,2 & 32 & 3 & 3 & 3 & 3 & 3 & 3 & ST81 \\
\hline Spain & Prunus dulcis 3 & 7 & 3 & 3 & 3 & 3 & 3 & 3 & ST7 \\
\hline Spain & Rhamnus alaternus 1 & 3 & 3 & 3 & 3 & 3 & 3 & 3 & ST6 \\
\hline Spain & Rosmarinus officinalis 4 & 3 & 3 & 3 & 3 & 3 & 3 & 3 & ST6 \\
\hline Spain & Rosmarinus officinalis 1,3 & 31 & 15 & 10 & 7 & 17 & 16 & 6 & ST80 \\
\hline Spain & Prunus domestica 3 & 3 & 3 & 3 & 3 & 3 & 3 & 3 & ST6 \\
\hline Spain & Philaenus spumarius $6,7,8,10,11$ & 1 & 1 & 1 & 1 & 1 & 1 & 1 & ST1 \\
\hline Spain & Philaenus spumarius 1 & 3 & 3 & 3 & 3 & 3 & 3 & 3 & ST6 \\
\hline Spain & Philaenus spumarius 22 & 32 & 3 & 3 & 3 & 3 & 3 & 3 & ST81 \\
\hline Spain & Neophilaenus campestris 1,2 & 3 & 3 & 3 & 3 & 3 & 3 & 3 & ST6 \\
\hline
\end{tabular}




\subsection{Nested-MLST Allowed Identification of New Alleles Among French Samples}

Incomplete profiles were obtained for various French samples due to variable amplification efficiencies varying according to the HKG. From 9\% (with $g l t T$ ) to 55\% (with holC) of French samples gave a signal applying the nested-MLST assay. Alleles that were not yet described in plant samples in France were detected in 2017. This was the case for holC_1 and holC_2 alleles known to occur in ST from ST1 to ST5 and ST75 that cluster in the subspecies fastidiosa (https://pubmlst.org/xfastidiosa/). These alleles were sequenced in samples of Asparagus acutifolius, Eleagnus, Cistus monspeliensis and C. creticus, Quercus ilex, Myrtus myrtifolia, Olea europaea, Platanus, Arbutus unedo (Table S5). Other holC alleles already described in STs clustering in the subspecies fastidiosa (holC_24) were also sequenced from Cistus monspeliensis and Pistaccia lentiscus. HolC_10 alleles described in STs clustering in the subspecies pauca were sequenced from Cistus monspeliensis and C. salicifolius, Cypressus, Metrosideros excelsa, Myrtus communis, Pistaccia lentiscus, Quercus ilex, Rubia peregrina, Smilax aspera samples. Similarly, holC_3 (known in ST6, ST7, ST25, ST34, ST35, ST79, ST81 and ST87 clustering in the subspecies multiplex) were obtained from samples of Acer monspeliensis, Arbutus unedo, Calicotome spinosa, Cistus monspeliensis, Genista corsica, Myrtus communis, Olea europaea, Phyllirea angustifolia, Polygala myrtifolia, Quercus ilex and Quercus pubescens, Spartium junceum. Among samples from 2018, only holC_1 allele was detected in Olea europaea, Quercus ilex, and Platanus sp. samples, and holC_3 allele in Cistus monspeliensis, Acer monspeliensis, Myrtus communis, and Polygala myrtifolia samples.

\subsection{Recombinants or Mixed Infections Were Identified by Nested-MLST}

Some French samples were further sequenced for several loci and these sequencing confirmed the presence of alleles occurring in the subspecies fastidiosa, multiplex and pauca (Table S5). All alleles were previously described but were detected in combinations that were not previously described, suggesting the presence of recombinants or of mix infections (Table S5). This is the case for Cistus monspeliensis 7 showing an unknown combination of cysG_2/petC_2/nuoL_2/gltT_2 (known in ST5) with malF_4 (known in ST2), both from subspecies fastidiosa; Helichrysum italicum 1 showing leuA_1 (known in subspecies fastidiosa) with petC_3/holC_3 known in subspecies multiplex; Myrtus communis 4 with leuA_3/holC_2 respectively known in subspecies multiplex and fastidiosa; Myrtus communis 8 and Platanus presenting form 1 alleles for five HKG mixed with malF_4 (all known in subspecies fastidiosa) and Q. ilex 10 presenting form 1 alleles for two HKG mixed with malF4); Olea europaea 2 with four multiplex alleles combined with nuoL_1 (subspecies fastidiosa); Olea europaea 5 with four pauca alleles combined with malF_15 (known in ST72 and ST76, subspecies fastidiosa). Two samples gave a double sequence for holC that were impossible to analyze (Table S5). Some sequences were ambiguous with superimposed peaks at some locations in otherwise good quality chromatograms revealing mixed infections. In those 12 samples, the number of potential combinations was too high to detect one probable allelic form, excepted for Prunus dulcis where the superimposed chromatograms corresponded to only two allelic forms (holC_3 or holC_6 which are found in subspecies multiplex). The holC_6 allelic form and the leuA_5 allele obtained for this sample are found in ST10, ST26, ST36, ST46, and ST63.

\section{Discussion}

A two-step nested procedure for MLST was developed to improve the typing of samples infected with low $X f$ population sizes that cannot be typed using the conventional protocol. In order not to affect the comparability of the results with the databases, the widely used MLST scheme developed for $X f$ that is supported by the pubMLST public website [22] was re-used.

The nested-MLST approach proved to be specific and efficient. No nonspecific amplifications were observed in any of the samples. Moreover, the sensitivities of the Harper's qPCR detection test and the nested-MLST were similar with a LoD ranging from $10^{3}$ bacteria. $\mathrm{mL}^{-1}$ to $10^{4}$ bacteria.mL $\mathrm{mL}^{-1}$ These LoDs are similar to other nested-MLST approaches such as those developed for Burkholderia 
cepacia [30] but higher than for the one developed for Neisseria meningitidis (10 copies $\left.\mathrm{mL}^{-1}\right)$ [31]. Consequently, in resource-limited settings where qPCR facilities are not available, the assay may be used as a useful diagnostic tool if applied with all necessary precautions to avoid cross-contamination between samples. The sequencing, which is costly, can be done as a consecutive but separate step to provide information on subspecies present in the sample. Higher bacterial loads (as indicated by lower Cq values) were observed in Spanish samples than in French samples, for which low amplification efficiency and partial profiles were observed. Full allelic profiles (ST6 and ST7 from multiplex subspecies) were obtained for Polygala myrtifolia, Spartium junceum and Genista corsica samples from France probably because they carried a higher bacterial load as shown by the low Cq obtained with the Harper's qPCR test: five of the six typed samples had a Cq value between 23.4 and 26.5. The use of the nested-MLST assay to type plant Spanish samples allowed a higher number of successful complete typing (55 samples versus seven samples with the conventional approach). Spanish samples generally showed higher $X f$ titer (i.e, lower Cq values in Harper's qPCR test) than the French samples but also concerned different plant species.

In our nested-MLST assay as well as in the original MLST assay, the amplification efficiencies were variable among genes, while all primers were designed using the same parameters from the software. For example, the holC gene for French samples tested with the nested-MLST assay was successfully amplified in 55\% of samples collected in 2017 while the gltT and nuoL genes gave the lowest rates (around 26\%). For samples collected in Spain tested with the original MLST assay, amplification rates among the seven HKGs ranged from 10 to $67 \%$. Success rate variations were also observed in medical research using MLST between samples and between loci [25]. When conducted on strains, no differences about amplification rates are observed because of DNA excess. Robustness of a PCR reaction is determined by appropriate primers and it is not always obvious why some primer combinations do not amplify well, even if some parameters such as DNA folding can interfere in PCR efficiency [32]. In this study, even if primer annealing temperature was adjusted, design of primers was limited by their arbitrary localization.

Typing results of French samples were concordant with previously published results [23] but also revealed the presence of alleles not yet described in France. It should be noticed that no unknown sequence was obtained, refraining from evoking contaminations as the origin of these yet undescribed alleles in France. Thanks to the high rate of amplification of holC in nested PCR, it was also possible to obtain sequences for equivocal samples (Cq with the Harper's qPCR test above 35) to confirm the presence of the bacterium in these samples. Surprisingly, these amplifications led to alleles that correspond to subspecies other than the multiplex subspecies. Thereby, alleles from subspecies pauca (holC_10) and fastidiosa (holC_1, holC_2, holC_24) were sequenced. holC_10 was already reported in Polygala myrtifolia in the south of France in 2015 [23]. holC_1 finding is in agreement with [24], who also reported holC_1 in insects in Corsica. Up to now, no holC_2 was reported in France but it is known in the USA. holC_24 was also reported in Polygala myrtifolia in Corsica in 2015 [23]. Further plant sampling efforts are needed to confirm the establishment of those strains in the environment or to document further the dynamics of alleles revealing sporadic infections.

For French samples only, several samples could not be typed since the chromatograms showed an overlap of two peaks precisely on the polymorphic sites (mainly with leuA and holC genes). This has already been reported by [23], it suggests the simultaneous presence of several strains in the same sample since only one copy of these genes are known in Xf [22]. Moreover, the report of previously unknown combination of alleles belonging to different subspecies can also results from the presence of co-infection or of recombinants. Recombination events are reported in $X f$ [23,33-35] and could have led to host shift [36]. In this study, eight samples presented unknown combinations of alleles from the same or different subspecies which could be explained by intrasubspecies or intersubspecies recombination events. As reported in [37], such events may exist and occur but not with the same frequency. Moreover, natural competence can be variable among Xf strains [38]. These events could also reflect a mechanism of adaptation [39]. Five samples among these eight samples were collected 
in 2017 and three in 2018, and were different between years. In 2018 the three cases were a similar combination of alleles and were found in three different plants. Future surveys will be necessary to know if some of these recombinants strains are indeed present in Corsica or are the consequence of mixed infections and if they have adapted and survived on different hosts.

The objective of this study was to improve the published MLST scheme supported by a public website (https://pubmlst.org/xfastidiosa/) by designing nested primers to lower the limit of detection and help in $X f$ diagnosis and typing. Thus, this improved MLST assay enables a higher sensitivity and specific typing of $X f$ directly from plant and insects samples without the need of isolating the strain and at an affordable cost.

Supplementary Materials: The following are available online at http://www.mdpi.com/2073-4395/10/8/1099/s1, Figure S1: detection threshold of conventional PCR for cysG and malF (Yuan et al., 2010) with and without BSA (final concentration at $\left.0.3 \mu \mathrm{g} . \mu \mathrm{L}^{-1}\right)$ using genomic DNA dilution range $\left(1: 220 \mathrm{ng} \cdot \mathrm{mL}^{-1} ; 2\right.$ : $22 \mathrm{ng} \cdot \mathrm{mL}^{-1} ; 3$ : 2.2ng. $\mathrm{mL}^{-1} ; 4$ : 220pg.mL $\mathrm{mL}^{-1} ; 5:$ 22pg.mL $\left.\mathrm{mL}^{-1} ; 6: 2.2 \mathrm{pg} \cdot \mathrm{mL}^{-1} ; 7: 220 \mathrm{fg} \cdot \mathrm{mL}^{-1} ; 8: 22 \mathrm{fg} \cdot \mathrm{mL}^{-1}\right)$. (+): positive control; (-) negative control, Table S1: List of X. fastidiosa genome sequences used in this study for primer and probe design (Denancé et al. 2019), Table S2: Primers properties, Table S3 Primer sequences alignment using a primer search tool available in the galaxy toolbox of CIRM-CFBP (https://iris.angers.inra.fr/galaxypub-cfbp) on 194438 bacterial Whole Genome Shotgun (WGS) sequences available in the NCBI database (as on March, 2019) including 58 Xylella and 1292 Xanthomonas, Table S4: detection threshold for Harper's qPCR test using genomic DNA dilution range (1: 220ng.mL-1; 2: 22ng.mL-1; 3: 2.2ng.mL-1; 4: 220pg.mL-1; 5: 22pg.mL-1; 6: 2.2pg.mL-1; 7: 220fg.mL-1; 8: 22fg.mL-1), Table S5: results obtained with qPCR and nested-MLST. $(+)$ means that a signal has been obtained in PCR but the PCR product has not been sequenced.

Author Contributions: Conceptualization, S.C.; methodology, S.C., E.D., M.B.; validation, S.C., Q.B.; formal analysis, B.B.L.; investigation, S.C., Q.B., M.M.-B., M.d.P.V.A.; resources, S.C., M.-A.J., M.M.-B., M.d.P.V.-A., B.B.L.; writing-Original draft preparation, S.C.; writing-Review and editing, S.C., E.D., M.-A.J., B.B.L.; visualization, S.C., B.B.L.; supervision, M.-A.J.; project administration, M.-A.J., B.B.L.; funding acquisition, M.-A.J., B.B.L. All authors have read and agreed to the published version of the manuscript.

Funding: ED salary was funded by INRA SPE division and Anses. This work received support from the European Union's Horizon 2020 research and innovation program under grant agreement 727987 XF-ACTORS (Xylella fastidiosa Active Containment Through a multidisciplinary-Oriented Research Strategy), and from Projects E-RTA2017-00004-C06-02 from 'Programa Estatal de I+D Orientada a los Retos de la Sociedad' from Spanish State Research Agency and from the Organización Interprofesional del Aceite de Oliva Español, CSIC Intramural Project 2018 40E111, and from “Conselleria de Agricultura, Desarrollo Rural, Emergencia Climática y Transición Ecológica" from Valencia region, and the Ministry of Agriculture, Fisheries and Food of Spain. The present work reflects only the authors'view and the EU funding agency is not responsible for any use that may be made of the information it contains.

Acknowledgments: We thank Muriel Bahut (ANAN technical facility, SFR QUASAV, Angers, FR) for DNA extraction automatization, CIRM-CFBP (Beaucouzé, INRA, France; http://www6.inra.fr/cirm_eng/CFBP-Plant Associated-Bacteria) for strain preservation and supply. We thank Ester Marco-Noales from the National Reference Laboratory for Phytopathogenic Bacteria (IVIA), and Diego Olmo from the Official Phytosanitary Laboratory of the Balearic Islands for providing DNA samples for MLST typing.

Conflicts of Interest: The authors declare no conflict of interest. The present work reflects only the authors'view and no analysis has been made in the French Reference Lab; in particular ED is not authorized to perform any official tests at Anses.

\section{Nomenclature}

$\begin{array}{ll}\text { BLAST } & \text { Basic Local Alignment Search Tool } \\ \text { Cq } & \text { quantification cycle } \\ \text { HKG } & \text { housekeeping gene } \\ \text { INRA } & \text { French National Institute for Agricultural Research } \\ \text { IRHS } & \text { Research Institute of Horticulture and Seeds } \\ \text { LoD } & \text { Limit of Detection } \\ \text { MLST } & \text { Multilocus Sequence Typing } \\ \text { NCBI } & \text { National Center for Biotechnology Information } \\ \text { ST } & \text { Sequence Type } \\ \text { Xf } & \text { Xylella fastidiosa } \\ \text { WGS } & \text { Whole Genome Shotgun }\end{array}$




\section{References}

1. Marcelletti, S.; Scortichini, M. Genome-Wide Comparison and Taxonomic Relatedness of Multiple Xylella Fastidiosa Strains Reveal the Occurrence of Three Subspecies and a New Xylella Species. Arch. Microbiol. 2016, 198, 803-812. [CrossRef]

2. Denancé, N.; Briand, M.; Gaborieau, R.; Gaillard, S.; Jacques, M.-A. Identification of Genetic Relationships and Subspecies Signatures in Xylella Fastidiosa. BMC Genom. 2019, 20, 239. [CrossRef] [PubMed]

3. EFSA (European Food Safety Authority). Scientific report on the update of the Xylella spp. host plant database. EFSA J. 2018, 16, 5408.

4. Janse, J.D.; Obradovic, A. XYLELLA FASTIDIOSA: ITS BIOLOGY, DIAGNOSIS, CONTROL AND RISKS. J. Plant Pathol. 2010, 14, S35-S48.

5. Almeida, R.P.P.; Nascimento, F.E.; Chau, J.; Prado, S.S.; Tsai, C.-W.; Lopes, S.A.; Lopes, J.R.S. Genetic Structure and Biology of Xylella Fastidiosa Strains Causing Disease in Citrus and Coffee in Brazil. AEM 2008, 74, 3690-3701. [CrossRef] [PubMed]

6. Coletta-filho, H.D.; Francisco, C.S.; Lopes, J.R.S.; de Oliveira, A.F.; Da Silva, L.F.d.O. First Report of Olive Leaf Scorch in Brazil, Associated with Xylella Fastidiosa subsp. pauca. Phytopathol. Mediterr. 2016, 55, $130-135$. [CrossRef]

7. Haelterman, R.M.; Tolocka, P.A.; Roca, M.E.; Guzmán, F.A.; Fernández, F.D.; Otero, M.L. FIRST PRESUMPTIVE DIAGNOSIS OF XYLELLA FASTIDIOSA CAUSING OLIVE SCORCH IN ARGENTINA. J. Plant Pathol. 2015, 1. [CrossRef]

8. Saponari, M.; Boscia, D.; Nigro, F.; Martelli, G.P. IDENTIFICATION OF DNA SEQUENCES RELATED TO XYLELLA FASTIDIOSA IN OLEANDER, ALMOND AND OLIVE TREES EXHIBITING LEAF SCORCH SYMPTOMS IN APULIA (SOUTHERN ITALY). J. Plant Pathol. 2013, 95. [CrossRef]

9. Wells, J.M.; Raju, B.C.; Hung, H.-Y.; Weisburg, W.G.; Mandelco-Paul, L.; Brenner, D.J. Xylella Fastidiosa Gen. Nov., Sp. Nov: Gram-Negative, Xylem-Limited, Fastidious Plant Bacteria Related to Xanthomonas Spp. Int. J. Syst. Bacteriol. 1987, 37, 136-143. [CrossRef]

10. PM 7/24 (4) Xylella Fastidiosa. EPPO Bull. 2019, 49, 175-227. [CrossRef]

11. Ouyang, P.; Arif, M.; Fletcher, J.; Melcher, U.; Ochoa Corona, F.M. Enhanced Reliability and Accuracy for Field Deployable Bioforensic Detection and Discrimination of Xylella Fastidiosa Subsp. Pauca, Causal Agent of Citrus Variegated Chlorosis Using Razor Ex Technology and TaqMan Quantitative PCR. PLoS ONE 2013, 8, e81647. [CrossRef] [PubMed]

12. Harper, S.J.; Ward, L.I.; Clover, G.R.G. Development of LAMP and Real-Time PCR Methods for the Rapid Detection of Xylella Fastidiosa for Quarantine and Field Applications. Phytopathology 2010, 100, 1282-1288. [CrossRef] [PubMed]

13. Bonants, P.; Griekspoor, Y.; Houwers, I.; Krijger, M.; van der Zouwen, P.; van der Lee, T.A.J.; van der Wolf, J. Development and Evaluation of a Triplex TaqMan Assay and Next-Generation Sequence Analysis for Improved Detection of Xylella in Plant Material. Plant Dis. 2019, 103, 645-655. [CrossRef] [PubMed]

14. Waliullah, S.; Hudson, O.; Oliver, J.E.; Brannen, P.M.; Ji, P.; Ali, M.E. Comparative Analysis of Different Molecular and Serological Methods for Detection of Xylella Fastidiosa in Blueberry. PLoS ONE 2019, 14, e0221903. [CrossRef]

15. Yaseen, T.; Drago, S.; Valentini, F.; Elbeaino, T.; Stampone, G.; Digiaro, M.; D'onghia, A.M. On-Site Detection of Xylella Fastidiosa in Host Plants and in "Spy Insects" Using the Real-Time Loop-Mediated Isothermal Amplification Method. Phytopathol. Mediterr. 2015, 54, 17-25. [CrossRef]

16. Burbank, L.P.; Ortega, B.C. Novel Amplification Targets for Rapid Detection and Differentiation of Xylella Fastidiosa Subspecies Fastidiosa and Multiplex in Plant and Insect Tissues. J. Microbiol. Methods 2018, 155, 8-18. [CrossRef]

17. Dupas, E.; Legendre, B.; Olivier, V.; Poliakoff, F.; Manceau, C.; Cunty, A. Comparison of Real-Time PCR and Droplet Digital PCR for the Detection of Xylella Fastidiosa in Plants. J. Microbiol. Methods 2019, 162, 86-95. [CrossRef]

18. Ciapina, L.P.; Carareto Alves, L.M.; Lemos, E.G.M. A Nested-PCR Assay for Detection of Xylella Fastidiosa in Citrus Plants and Sharpshooter Leafhoppers. J. Appl. Microbiol. 2004, 96, 546-551. [CrossRef] 
19. Guan, W.; Shao, J.; Singh, R.; Davis, R.E.; Zhao, T.; Huang, Q. A TaqMan-Based Real Time PCR Assay for Specific Detection and Quantification of Xylella Fastidiosa Strains Causing Bacterial Leaf Scorch in Oleander. J. Microbiol. Methods 2013, 92, 108-112. [CrossRef]

20. Dupas, E.; Briand, M.; Jacques, M.-A.; Cesbron, S. Novel Tetraplex Quantitative PCR Assays for Simultaneous Detection and Identification of Xylella Fastidiosa Subspecies in Plant Tissues. Front. Plant Sci. 2019, 10, 1732. [CrossRef]

21. Scally, M.; Schuenzel, E.L.; Stouthamer, R.; Nunney, L. Multilocus Sequence Type System for the Plant Pathogen Xylella Fastidiosa and Relative Contributions of Recombination and Point Mutation to Clonal Diversity. AEM 2005, 71, 8491-8499. [CrossRef] [PubMed]

22. Yuan, X.; Morano, L.; Bromley, R.; Spring-Pearson, S.; Stouthamer, R.; Nunney, L. Multilocus Sequence Typing of Xylella Fastidiosa Causing Pierce's Disease and Oleander Leaf Scorch in the United States. Phytopathology 2010, 100, 601-611. [CrossRef] [PubMed]

23. Denancé, N.; Legendre, B.; Briand, M.; Olivier, V.; de Boisseson, C.; Poliakoff, F.; Jacques, M.-A. Several Subspecies and Sequence Types Are Associated with the Emergence of Xylella Fastidiosa in Natural Settings in France. Plant Pathol. 2017, 66, 1054-1064. [CrossRef]

24. Cruaud, A.; Gonzalez, A.-A.; Godefroid, M.; Nidelet, S.; Streito, J.-C.; Thuillier, J.-M.; Rossi, J.-P.; Santoni, S.; Rasplus, J.-Y. Using Insects to Detect, Monitor and Predict the Distribution of Xylella Fastidiosa: A Case Study in Corsica. Sci. Rep. 2018, 8, 15628. [CrossRef] [PubMed]

25. Weiss, S.; Menezes, A.; Woods, K.; Chanthongthip, A.; Dittrich, S.; Opoku-Boateng, A.; Kimuli, M.; Chalker, V. An Extended Multilocus Sequence Typing (MLST) Scheme for Rapid Direct Typing of Leptospira from Clinical Samples. PLoS Negl. Trop Dis. 2016, 10, e0004996. [CrossRef] [PubMed]

26. Van der Veer, C.; Himschoot, M.; Bruisten, S.M. Multilocus Sequence Typing of Trichomonas Vaginalis Clinical Samples from Amsterdam, the Netherlands. BMJ Open 2016, 6, e013997. [CrossRef]

27. Mougel, C.; Cournoyer, B.; Nesme, X. Novel Tellurite-Amended Media and Specific Chromosomal and Ti Plasmid Probes for Direct Analysis of Soil Populations of Agrobacterium Biovars 1 and 2. Appl. Environ. Microbiol. 2001, 67, 65-74. [CrossRef]

28. King, E.O.; Ward, M.K.; Raney, D.E. Two simple media for the demonstration of pyocyanin and fluorescin. J. Lab. Clin. Med. 1954, 44, 301-307.

29. Doležel, J.; Bartos, J.; Voglmayr, H.; Greilhuber, J. Letter to the Editor. Cytometry 2003, 51, 127-128. [CrossRef]

30. Drevinek, P.; Vosahlikova, S.; Dedeckova, K.; Cinek, O.; Mahenthiralingam, E. Direct Culture-Independent Strain Typing of Burkholderia Cepacia Complex in Sputum Samples from Patients with Cystic Fibrosis. J. Clin. Microbiol. 2010, 48, 1888-1891. [CrossRef]

31. Diggle, M.A.; Bell, C.M.; Clarke, S.C. Nucleotide Sequence-Based Typing of Meningococci Directly from Clinical Samples. J. Med. Microbiol. 2003, 52, 505-508. [CrossRef] [PubMed]

32. Bustin, S.; Huggett, J. QPCR Primer Design Revisited. Biomol. Detect. Quantif. 2017, 14, 19-28. [CrossRef] [PubMed]

33. Jacques, M.-A.; Denancé, N.; Legendre, B.; Morel, E.; Briand, M.; Mississipi, S.; Durand, K.; Olivier, V.; Portier, P.; Poliakoff, F.; et al. New Coffee Plant-Infecting Xylella Fastidiosa Variants Derived via Homologous Recombination. Appl. Environ. Microbiol. 2016, 82, 1556-1568. [CrossRef]

34. Nunney, L.; Hopkins, D.L.; Morano, L.D.; Russell, S.E.; Stouthamer, R. Intersubspecific Recombination in Xylella Fastidiosa Strains Native to the United States: Infection of Novel Hosts Associated with an Unsuccessful Invasion. Appl. Environ. Microbiol. 2014, 80, 1159-1169. [CrossRef] [PubMed]

35. Saponari, M.; D’Attoma, G.; Abou Kubaa, R.; Loconsole, G.; Altamura, G.; Zicca, S.; Rizzo, D.; Boscia, D. A New Variant of Xylella Fastidiosa Subspecies Multiplex Detected in Different Host Plants in the Recently Emerged Outbreak in the Region of Tuscany, Italy. Eur. J. Plant Pathol. 2019, 154, 1195-1200. [CrossRef]

36. Nunney, L.; Schuenzel, E.L.; Scally, M.; Bromley, R.E.; Stouthamer, R. Large-Scale Intersubspecific Recombination in the Plant-Pathogenic Bacterium Xylella Fastidiosa Is Associated with the Host Shift to Mulberry. Appl. Environ. Microbiol. 2014, 80, 3025-3033. [CrossRef]

37. Potnis, N.; Kandel, P.P.; Merfa, M.V.; Retchless, A.C.; Parker, J.K.; Stenger, D.C.; Almeida, R.P.P.; Bergsma-Vlami, M.; Westenberg, M.; Cobine, P.A.; et al. Patterns of Inter- and Intrasubspecific Homologous Recombination Inform Eco-Evolutionary Dynamics of Xylella Fastidiosa. ISME J. 2019, 13, $2319-2333$. [CrossRef] 
38. Kandel, P.P.; Almeida, R.P.P.; Cobine, P.A.; De La Fuente, L. Natural Competence Rates Are Variable among Xylella Fastidiosa Strains and Homologous Recombination Occurs in Vitro Between Subspecies Fastidiosa and Multiplex. MPMI 2017, 30, 589-600. [CrossRef]

39. Kandel, P.P.; Lopez, S.M.; Almeida, R.P.P.; De La Fuente, L. Natural Competence of Xylella Fastidiosa Occurs at a High Frequency Inside Microfluidic Chambers Mimicking the Bacterium's Natural Habitats. Appl. Environ. Microbiol. 2016, 82, 5269-5277. [CrossRef]

(C) 2020 by the authors. Licensee MDPI, Basel, Switzerland. This article is an open access article distributed under the terms and conditions of the Creative Commons Attribution (CC BY) license (http://creativecommons.org/licenses/by/4.0/). 